\title{
Aspirin Causes Lipid Accumulation and Damage to Cell Membrane by Regulating DC/1/OLE1 in Saccharomyces cerevisiae
}

\author{
Pan Zhu, ${ }^{1}$ Ming Li, ${ }^{1}$ Chongjia Yan, ${ }^{1}$ Jing Sun, ${ }^{2}$ Min Peng, ${ }^{2}$ Zhiwei Huang, ${ }^{3}$ and Ping Shi ${ }^{1}$
}

Aspirin is one of the most commonly used nonsteroidal anti-inflammatory drugs. Various potential pharmacological effects of aspirin, such as anticancer, antibacterial activity, and prolonging life expectancy have been discovered. However, the mechanism of aspirin is not fully elucidated. Herein, the effects of aspirin on fatty acid metabolism in yeast cell model Saccharomyces cerevisiae were studied. The results showed that aspirin can induce lipid accumulation and reduce the unsaturated fat index in cells. The assessment of cell membrane integrity demonstrated that aspirin caused damage to the cell membrane. These effects of aspirin were attributed to the alterations of the expression of DCII and OLE1. Similarly, aspirin was able to cause lipid accumulation and damage to the cell membrane by interfering with the expression of OLE1 in Candida albicans. These findings are expected to improve current understanding of the mode of action of aspirin and provide a novel strategy for antifungal drug design.

\section{Graphical Abstract}

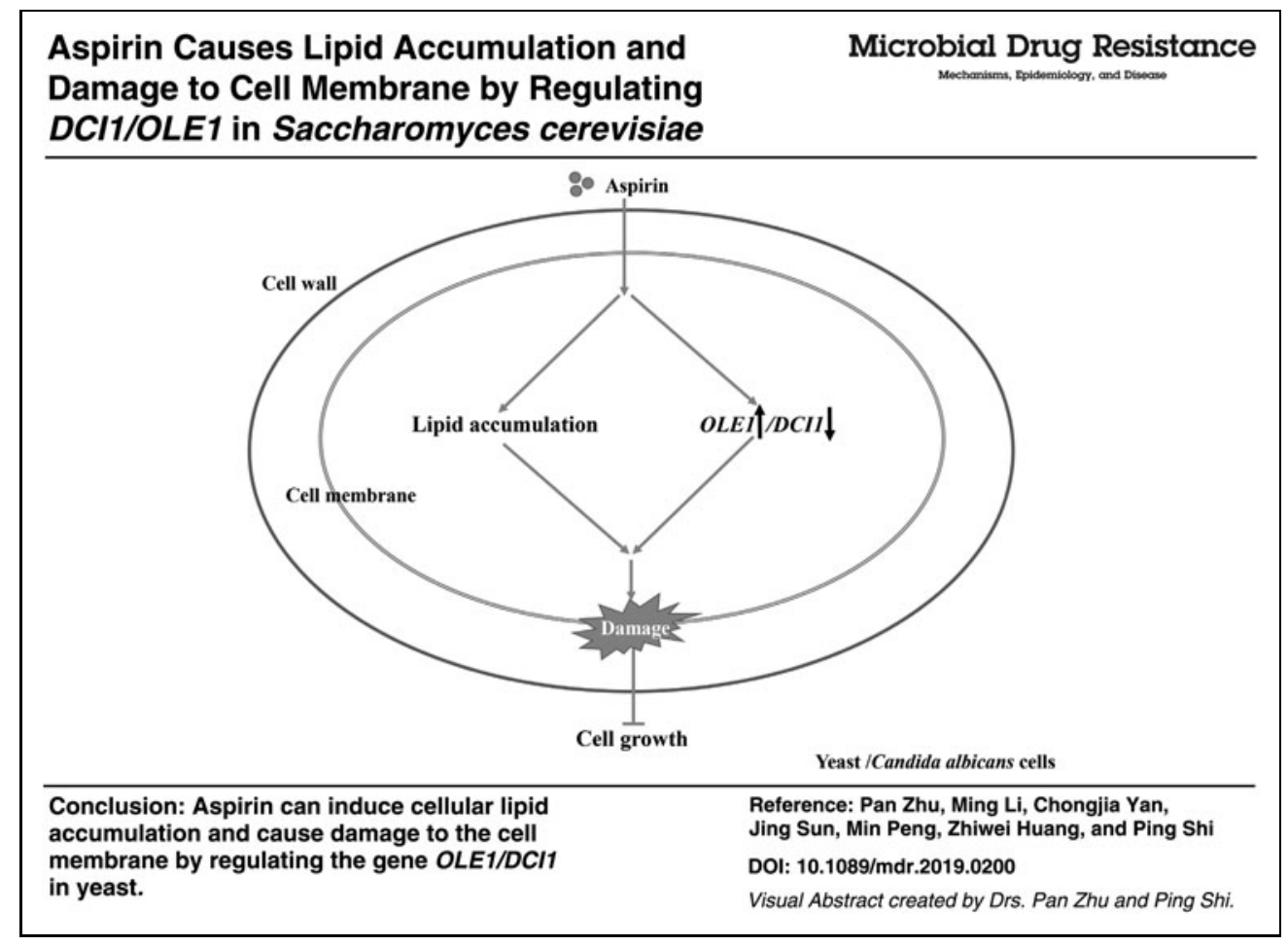

\footnotetext{
${ }^{1}$ State Key Laboratory of Bioreactor Engineering, East China University of Science and Technology, Shanghai, China.

${ }^{2}$ Qinghai Key Laboratory of Qinghai-Tibet Plateau Biological Resources, Northwest Institute of Plateau Biology, the Chinese Academy of Sciences, Xining, Qinghai, China.

${ }^{3}$ Key Lab of Eco-Textile, Ministry of Education, College of Chemistry, Chemical Engineering and Biotechnology, Donghua University, Shanghai, China.
} 
Keywords: aspirin, Saccharomyces cerevisiae, fatty acid metabolism, OLE1, DCI1

\section{Introduction}

A SPIRIN, OR ACETYLSALICYLIC acid (ASA), is a historical nonsteroidal anti-inflammatory drug (NSAIDs) and is in widespread use for the treatment and prevention of numerous medical conditions, such as fever, pain, and inflammation. ${ }^{1,2}$ In recent years, it has been reported that aspirin might have potential effect of anticancer, antibacterial activity, and prolonging life expectancy. ${ }^{3-5}$

A number of studies have focused on the mechanisms of aspirin in different fields of fungal biology. For instance, Alem and Douglas found that aspirin shows a significant inhibition on Candida albicans by reducing the viability of biofilm organisms. ${ }^{6}$ Sapienza and Balzan reported that aspirin renders Saccharomyces cerevisiae more vulnerable to an altered redox balance and leads to growth arrest by affecting negatively the glutathione (GSH)/glutathione disulfide (GSSG) ratio, which induces apoptosis. ${ }^{7}$ Farrugia et al. proved that the apoptosis induced by aspirin is associated with the a significant increase in mitochondrial and cytosolic $\mathrm{O}_{2}{ }^{-}$and oxidation of mitochondrial nicotinamide adenine dinucleotide phosphate hydrogen. ${ }^{8}$ However, the mechanism underlying the effect of aspirin is still unclear.

The budding yeast $S$. cerevisiae is a beneficial model organism for many biological systems. ${ }^{9}$ It not only has a relatively short life span and is stable in both haploid and diploid forms, ${ }^{10,11}$ but also can quickly and efficiently respond to stress phenomena resulting from environmental or nutritional insult. ${ }^{12}$ Due to these advanced properties, $S$. cerevisiae has been widely applied to biochemical, genetic, and cytological studies in fundamental cellular processes. ${ }^{13}$ In addition, the implementation and validation of various new genomic technologies in yeast, such as druginduced phenotypic responses, ${ }^{14}$ synthetic lethal screens, ${ }^{15}$ drug-induced haploinsufficiency ${ }^{16}$ and gene expression profiling of drug actions, ${ }^{17}$ has enabled $S$. cerevisiae as an ideal model organism to explore action of drugs or to identify new molecular entities with therapeutic potential.

The present study is designed to discover the potential targets of aspirin by using $S$. cerevisiae as a model organism and illuminate the potential mechanism of aspirin as an antifungal agent. The evidence shows that aspirin has the ability to induce lipid accumulation. Additionally, the target genes DCII and OLE1 that could be affected by aspirin in lipid metabolism have been identified. DCI1 and OLE1 are the key oxidase and synthetase in fatty acid metabolism, respectively. ${ }^{18}$ Deletion of $D C I I$ can cause a growth defect of yeast on oleic acid medium, ${ }^{19}$ whereas growth of ole1 $\Delta$ requires supplemental oleic acid in the medium. ${ }^{20}$ In line with these findings, aspirin can cause cell membrane damage by inhibiting expression of OLE1 in C. albicans cells. This study is expected to fill the gaps in understanding the molecular mechanism of aspirin.

\section{Materials and Methods}

Yeast strains, media, and growth conditions

The C. albicans (CMCC96001) and wild-type strain S. cerevisiae BY4741 and its mutant strains, including $m g a 2 \Delta, e c l 1 \Delta, e c m 31 \Delta$, and $d c i 1 \Delta$ used in the present study, are listed in Table 1. The seeds of yeast strains were grown from overnight cultures on yeast extract peptone dextrose media ( $1 \%$ yeast extract, $2 \%$ peptone, and $2 \%$ glucose). Cells were pelleted and washed twice immediately after the cells had grown till the mid exponential phase. Then, cells were inoculated at 0.1 of $\mathrm{OD}_{600}$ in synthetic complete (SC) media $(0.67 \%$ yeast nitrogen base, $2.0 \%$ glucose, and complete amino acid mixture) or SC-Ura medium initially containing $0,0.125,0.25$, and $0.5 \mathrm{mg} / \mathrm{mL}$ aspirin, respectively. Yeast extract and tryptone were obtained from Oxoid Ltd (Basingstoke, Hampshire, England). D-Glucose was obtained from Shanghai Lingfeng Chemical Reagent Co., Ltd. Other chemicals were purchased from Sangon Biotech (Shanghai, China). Aspirin (Sigma Chemical Co, St Louis) was freshly dissolved in dimethylsulphoxide (Sigma).

\section{Screening for potential target genes of aspirin}

Screening for potential target genes of aspirin by haploid yeast knockouts (YKOs) was carried out essentially as previously described. ${ }^{21,22}$ Pools of isogenic MATa haploid cells were derived by growth on a haploid selection medium that either contained (experiment) or lacked (control) aspirin at $0.25 \mathrm{mg} / \mathrm{mL}$. Relative representation of each YKO in drug-treated and untreated pools was compared by bar code microarray analysis.

\section{Confirmation for potential target genes of aspirin and drug susceptibility assay}

The drug sensitivity of yeast strains was determined via the drop test technique. In brief, yeast cells $\left(\mathrm{OD}_{600} 1.0\right)$ were obtained from a single clone on medium and harvested. Each yeast strains were serially diluted 10-fold, spotted on SC plates or SC-Ura plates supplemented with $0,0.125$, $0.25 \mathrm{mg} / \mathrm{mL}$ aspirin, and incubated at $30^{\circ} \mathrm{C}$ for $4-7$ days.

\section{Effect of aspirin on lipid accumulation in S. cerevisiae and $\mathrm{C}$. albicans}

To visualize Oil red O-stained cells, samples were processed and observed as described. ${ }^{23} \mathrm{~A}$ total of $2 \times 10^{7}$ cells treated with $0,0.125$, and $0.25 \mathrm{mg} / \mathrm{mL}$ aspirin for 24 hours were harvested and stained with working solution of Oil red $\mathrm{O}$ (the ratio of $1 \%$ stock in isopropanol to $\mathrm{H}_{2} \mathrm{O}$ is 3-2) for 10 minutes, then washed with distilled water and observed by fluorescence microscopy (Nikon Eclipse TI) at excitation wavelength of $488 \mathrm{~nm}$, emission wavelength of $670 \mathrm{~nm}$.

Table 1. Yeast Strains in This Study

\begin{tabular}{|c|c|c|}
\hline Strains & Feature & Origin \\
\hline BY4741 & MATahis $3 \Delta$ lleu $2 \Delta$ Oura $3 \Delta 0$ & Invitrogen \\
\hline dcils & BY4741 dcil $\triangle::$ KanMX4 & Invitrogen \\
\hline$m g a 2 \Delta$ & BY4741 mga2 $::$ KanMX4 & Invitrogen \\
\hline ecll $\Delta$ & BY4741 ecll $\Delta::$ KanMX4 & Invitrogen \\
\hline ecm31 & BY4741 ecm $31 \Delta::$ KanMX4 & Invitrogen \\
\hline
\end{tabular}


Transmission images were recorded by differential interference contrast (DIC) optics.

\section{Effect of aspirin on cellular saturated and monounsaturated fatty acids}

Cellular lipids of different yeast strains were extracted as described with little modification. ${ }^{24,25}$ Fatty acid methyl esters were prepared and detected by a modified method. ${ }^{26}$ Briefly, $2 \times 10^{8}$ cells grown on SC mediums for 24 hours were harvested, washed three times and decentralized in $1 \mathrm{~mL}$ ultrapure water. A VCX150 sonicator (Sonics \& Materials Co. Ltd.) was used for yeast cell lysis at $150 \mathrm{~W}$ and $20 \mathrm{kHz}$ frequency for 10 minutes. Two milliliter methyl alcohol was added into yeast cell lysis and vibrated for 5 minutes. Then, $2 \mathrm{~mL}$ chloroform was added immediately and vibrated for another 5 minutes. After centrifugation at $4,000 \mathrm{~g}$ for 10 minutes, the bottom layer was transferred to a new centrifugal tube to dry under nitrogen gas. Two moles per liter sodium hydroxide in methanol- $\mathrm{H}_{2} \mathrm{O}(1: 1,[\mathrm{vol} / \mathrm{vol}])$ solution was added into total lipid, followed immediately by heating at $100^{\circ} \mathrm{C}$ for 5 minutes. Three milliliter $2 \mathrm{~mol} / \mathrm{L}$ hydrogen chloride in methanol solution was added and the solution was heated at $85^{\circ} \mathrm{C}$ for 1 hour. Two milliliter hexane was used to extract the methyl esters of fatty acids. The upper layer was collected and transferred into new $1.5 \mathrm{~mL}$ plastic tubes and dried under nitrogen gas after centrifugation at $10,000 \mathrm{~g}$ at $4^{\circ} \mathrm{C}$ for 10 minutes. For the analysis of the methyl esters of fatty acids, Agilent $6890 \mathrm{~N}$ gas chromatograph equipped with a 5975-mass spectrometer (Agilent) was used. The Gas Chromatography-Mass Spectrometry (GC-MS) was equipped with an HP-5 $(30 \mathrm{~m} \times 0.25 \mathrm{~mm}, 0.25 \mu \mathrm{m}$ film thickness $)$ column for analysis. The temperature program was set from initial temperature at $80-280^{\circ} \mathrm{C}$ at a rate of $20^{\circ} \mathrm{C} /$ minutes and maintained at $280^{\circ} \mathrm{C}$ for 5 minutes. Methyl undecanoate (C11:0) was used as internal standard. Helium was used as a carrier gas and the injection volume was $1 \mu \mathrm{L}$.

\section{Effect of aspirin on mRNA expression of DCl1 and OLE1}

One to two milliliters of aspirin treated and aspirin nontreated cells at $\mathrm{OD}_{600}$ three to five were harvested and washed with cold water three times. Total RNA was extracted and purified using Yeast RNAiso Kit (TaKaRa, Tokyo, Japan) as described by the manufacturer. One microgram RNA was reverse-transcribed using Reverse Transcription kit (TaKaRa). Quantitative real-time assays were performed using EmeraldAmp PCR Master Mix (TaKaRa) and SYBR
Premix Ex Taq (TaKaRa). DCI1, OLE1, ACT1, and MGA2 in S. cerevisiae and OLE1, SPT23, and ACT1 in C. albicans were amplified by Quantitative real-time PCR assays using the primers in Table 2 .

\section{Effect of aspirin on cell membrane integrity}

The integrity of cellular membrane was studied by using propidium iodide (PI) as described previously. ${ }^{27}$ Cells grown on SC media were harvested by centrifugation at $5,000 \mathrm{rpm}$ for 5 minutes at $4^{\circ} \mathrm{C}$ after treatment with different aspirin for 24 hours. They were then washed twice with distilled water. PI $(1 \mathrm{mg} / \mathrm{mL})$ was added to $100 \mu \mathrm{L}$ of the cell suspensions to yield a final concentration of $10 \mu \mathrm{g} / \mathrm{mL}$. After 15 minutes of incubation at room temperature, cells were examined by DIC microscopy and fluorescent microscope (Nikon Eclipse TI) at excitation wavelength of $488 \mathrm{~nm}$, emission wavelength of $670 \mathrm{~nm}$ and then counted. The percentages of cells exhibiting red fluorescence were plotted. Each value was obtained from three independent experiments.

\section{Statistical analysis}

All experiments were performed at least three times. Values were expressed as mean \pm standard deviations. A Student's $t$-test was used for statistical analysis. Values of $p<0.05$ were considered to be statistically significant.

\section{Results}

Aspirin inhibited the growth of $\mathrm{C}$. albicans and $\mathrm{S}$. cerevisiae, and induced lipid accumulation in yeast cells

First, the pathogen $C$. albicans and the yeast $S$. cerevisiae cells were grown in SC media containing $0,0.125,0.25,0.5$, and $0.75 \mathrm{mg} / \mathrm{mL}$ aspirin, respectively. As shown in Fig. 1A and $\mathrm{B}$, the growth of both cell types was inhibited in a dosedependent manner. Cells treated with 0.125 and $0.25 \mathrm{mg} / \mathrm{mL}$ aspirin can incur $25 \%$ and $50 \%$ repression on cell growth, respectively. Hence, 0.125 and $0.25 \mathrm{mg} / \mathrm{mL}$ were used in the following experiments.

To identify the potential targets of aspirin, we first systematically screened the yeast $S$. cerevisiae genome-wide haploid deletion mutants as described in the methods, and classified these resistance and sensitivity genes into four groups, nonspecific drug resistance genes, cell membrane-related genes, cell wall integrity-related genes, and energy metabolismrelated genes (Supplementary Fig. S1). According to the result of the screening, MGA2 classified to cell membrane-related genes group was highly repressed by aspirin (Supplementary

Table 2. Primer Sets Used in PCR

\begin{tabular}{lll}
\hline & \multicolumn{1}{c}{ Forward $\left(5^{\prime}-3^{\prime}\right)$} & \multicolumn{1}{c}{ Reverse $\left(5^{\prime}-3^{\prime}\right)$} \\
\hline Genes in yeast & & \\
$D C I 1$ & CTCCTAACATATTTGTGGCGAAC & \\
OLE1 & CTACTACGCTGTCGGTGGTG & CTCTGCGACAAAACCGAGA \\
MGA 2 ACCAGGATGATAGCATGGCG & AAGCATTAGCGGACCCTT \\
Genes in Candida albicans & GCTTTGTCCATCCTTCTG & GAAACACTTGTGGTGAACG \\
OLE1 & CTTTGGTTGCTGGATTGGGC & \\
SPT23 & TTCGGCACCTAGTTCATCGG & GGCCAAGGAGTTGACACAGA \\
ACT1 & AGGTTTGGAAGCTGCTGGTA & GGCTAAAGCTTCAGATGCCG \\
\hline
\end{tabular}



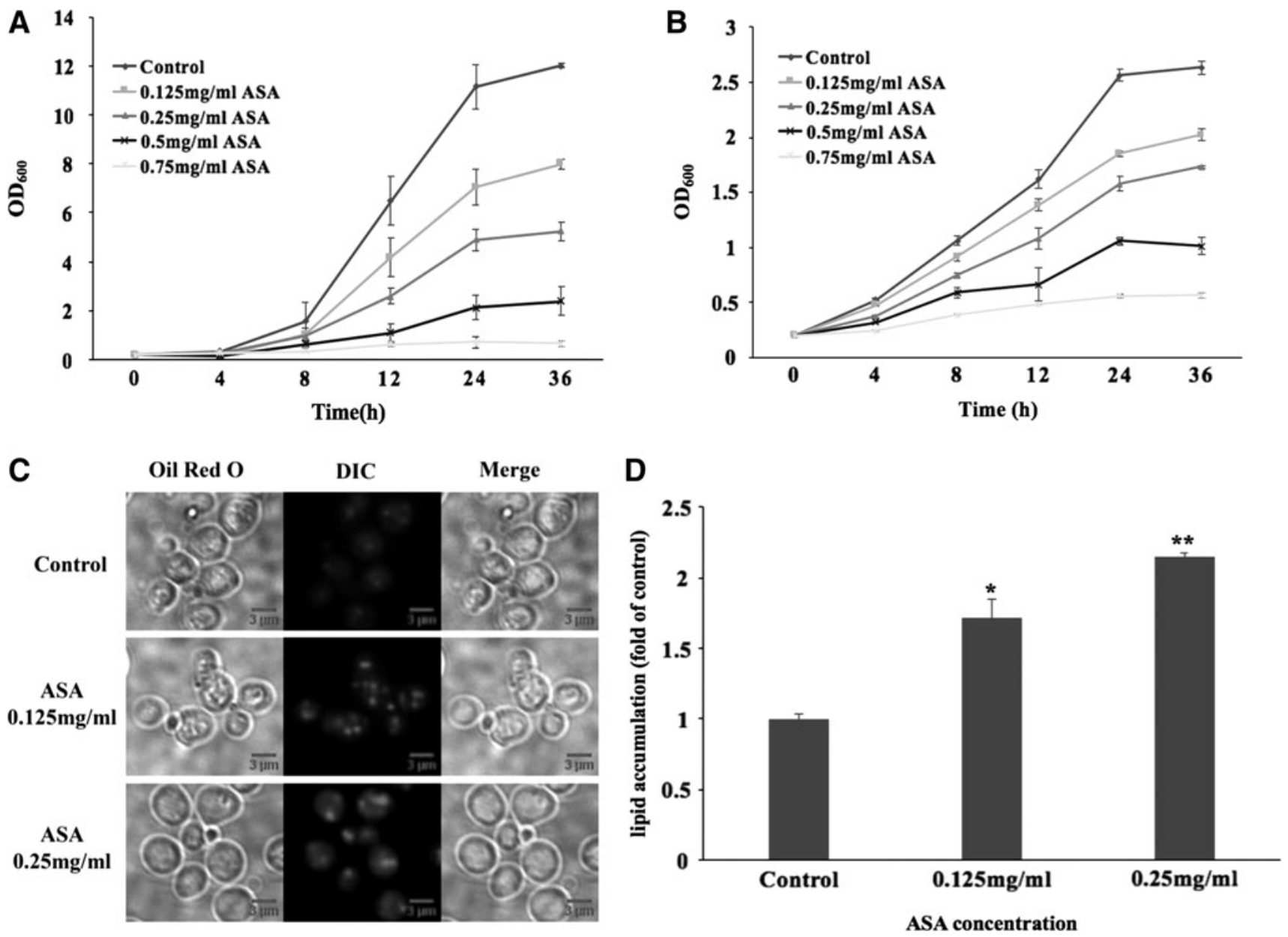

FIG. 1. Aspirin inhibited the growth of Candida albicans and yeast and introduced lipid accumulation in wild-type yeast. (A) The growth curve of C. albicans on addition of aspirin. C. albicans cells were grown in the presence of $0,0.125,0.25$, 0.5 , and $0.75 \mathrm{mg} / \mathrm{mL}$. (B) The growth curve of budding yeast cells on addition of aspirin. The wild-type cells were grown in the presence of $0,0.125,0.25,0.5$, and $0.75 \mathrm{mg} / \mathrm{mL}$ aspirin. (C) Intracellular lipid droplets of wild type were stained with Oil Red $\mathrm{O}$ and photographed by DIC microscopy and fluorescence microscopy with $\times 400$ magnification, scale bar is $2 \mu \mathrm{m}$. Concentration of aspirin was 0.125 and $0.25 \mathrm{mg} / \mathrm{mL}$, respectively. (D) Quantification of lipid accumulation in wild type under 0.125 and $0.25 \mathrm{mg} / \mathrm{mL}$ aspirin treatment. Values were expressed as mean \pm SD. $* p<0.05$. $* * p<0.01$ (drug-treated group vs. control group). DIC, differential interference contrast; SD, standard deviation.

Table S1, Supplementary Fig. S1). In fact, $M G A 2$ is also involved in regulation of OLE1 transcription ${ }^{28}$ and it has been reported that aspirin has a great influence on fatty acid metabolism in mammal cells. ${ }^{29}$ Thereby, we were curious about the impact of aspirin on fatty metabolism in yeast. As shown in Fig. 1C, aspirin resulted in an increase of lipid accumulation when compared with the control group. The quantification in Fig. 1D indicates that aspirin can induce cellular lipid accumulation in yeast.

\section{Aspirin regulates the expression of $\mathrm{DCl} 1$ and OLE1 genes in yeast cells}

To further identify the potential target genes of aspirin, mutants lacking fatty acid metabolism-related genes were chosen based on the screening result. Mutants were selected and investigated by spot assay technique (Table 1). As shown in Fig. 2A, dcil $\Delta$ mutants show super resistance toward aspirin, whereas mga2 $\Delta$ mutants show susceptibility toward aspirin. Interestingly, DCII encodes the delta $(3,5)$-delta $(2,4)$-dienoyl-
CoA isomerase involved in beta-oxidation of fatty acids, ${ }^{30}$ whereas $M G A 2$ is an important transcription factor of $O L E 1$ that encodes delta (9) fatty acid desaturase required for monounsaturated fatty acid synthesis. ${ }^{28}$ These two genes with different functions show opposite results after drug susceptibility assay, indicating that aspirin may inhibit cell growth by impacting the components of fatty acid through these two genes.

Quantitative real-time PCR analysis was then performed to explore the effect of aspirin on DCI1, MGA2, and OLE1 expression. $M G A 2$ and $O L E 1$ were suppressed in dosedependent manners, while the expression of $D C I 1$ was upregulated by aspirin (Fig. 2B).

To confirm the results, we analyzed the effects of $D C I 1$ and $O L E 1$ on drug-resistant stress by spot testing. Since $O L E 1$ is an essential gene for yeast, mga2 $\Delta$ is used to produce low level of expression of $O L E 1$. The results in Fig. 2C and D show that overexpression of DCII causes the cells to become more susceptible to aspirin. However, when overexpressing OLE1 in the cells, only the BY4741 and mga $2 \Delta$ exhibited resistance to aspirin (Fig. 2C, D). 

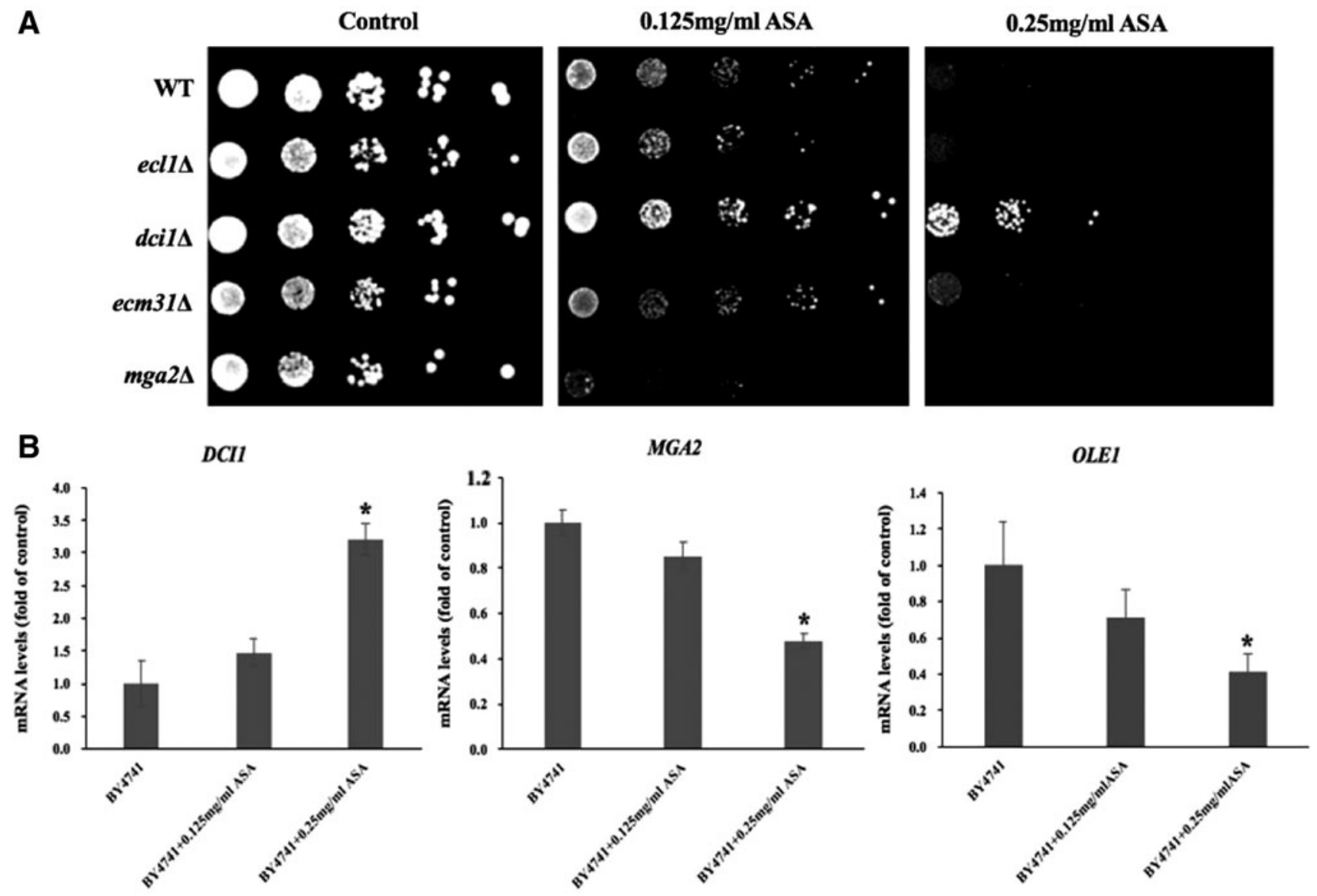

C
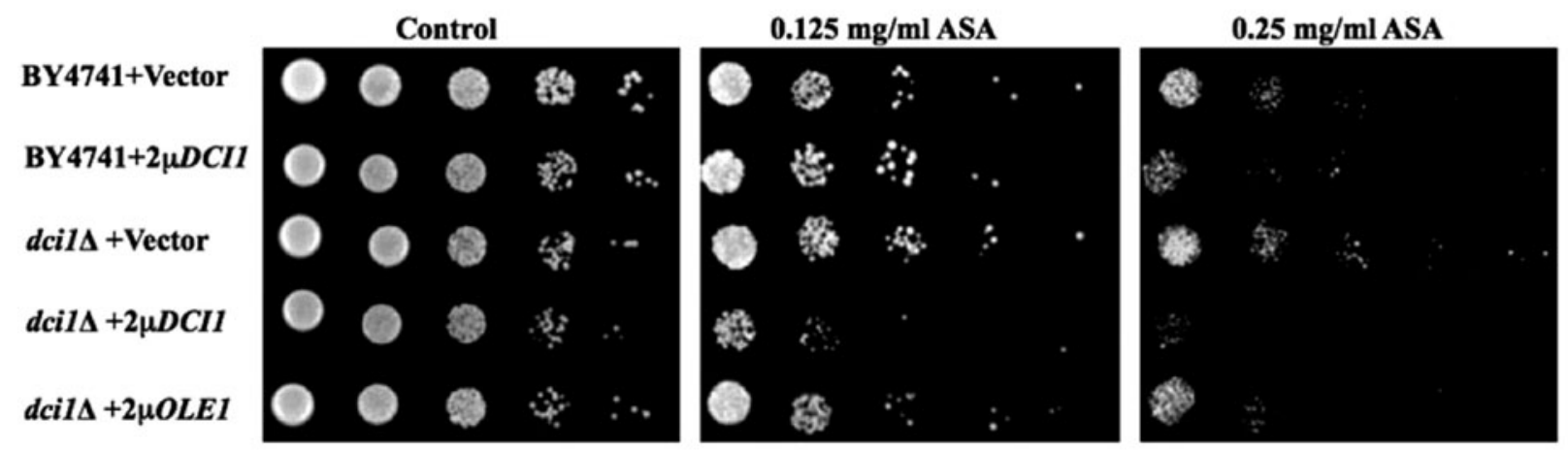

D
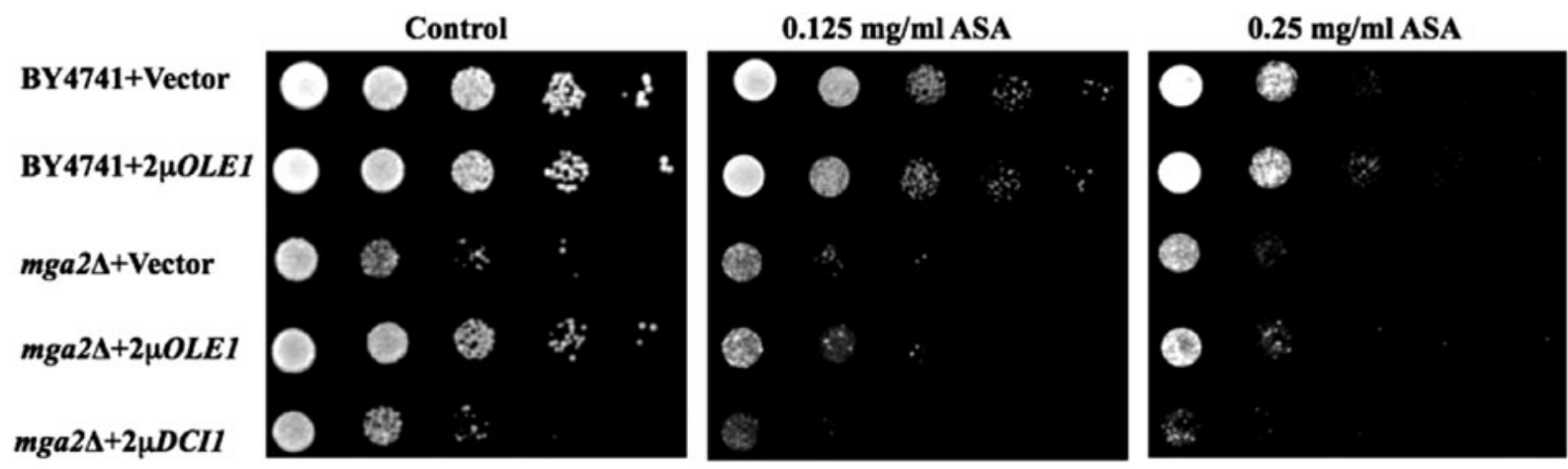

FIG. 2. Aspirin inhibits the growth of yeast by $d c i 1$ and ole 1 genes. (A) Spot assay. Strains lacking fatty acid metabolismrelated genes were selected from yeast mutant library, were grown for 3-7 days on SC plates with different concentration of aspirin, 10-fold serially diluted, and then spotted on plates. (B) Quantitative real-time PCR analysis. The mRNA expression of DCI1, MGA2, and OLE1 was confirmed by real-time PCR analysis and normalized to ACT1 RNA expression. Values were expressed as mean \pm SD. $* p<0.05$ (drug-treated group vs. corresponding control group). (C, D) Spot assay. BY4741, $d c i 1 \triangle$, mga2 $\triangle$ cells carrying vector or the $O L E 1, D C I 1$ plasmid were grown on SC-Ura plates with or without the addition of 0.125 and $0.25 \mathrm{mg} / \mathrm{mL}$ aspirin and were incubated at $30^{\circ} \mathrm{C}$ for $3-7$ days. SC, synthetic complete. 
A

ASA

$0.125 \mathrm{mg} / \mathrm{ml}$

ASA $0.25 \mathrm{mg} / \mathrm{ml}$

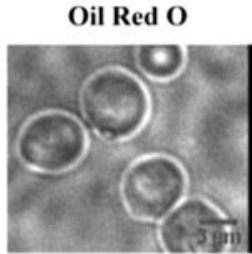

DIC

Merge
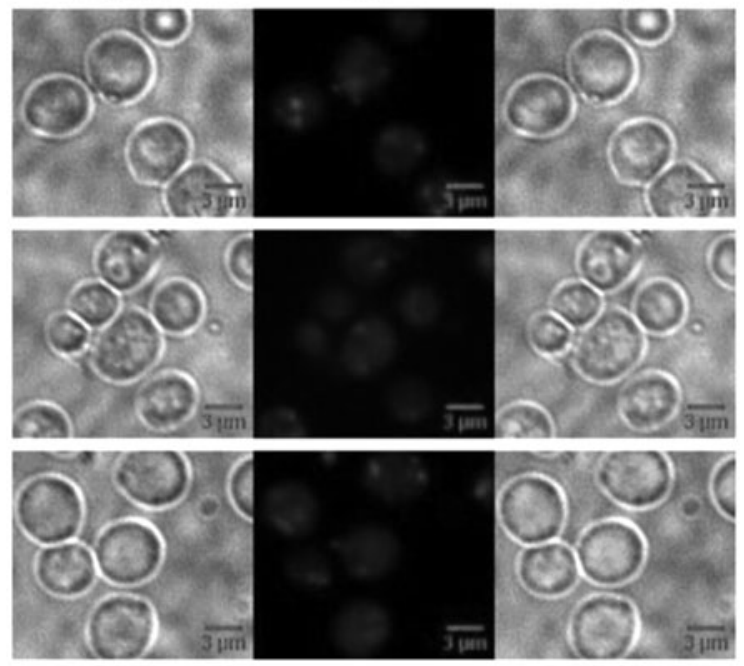

dcils
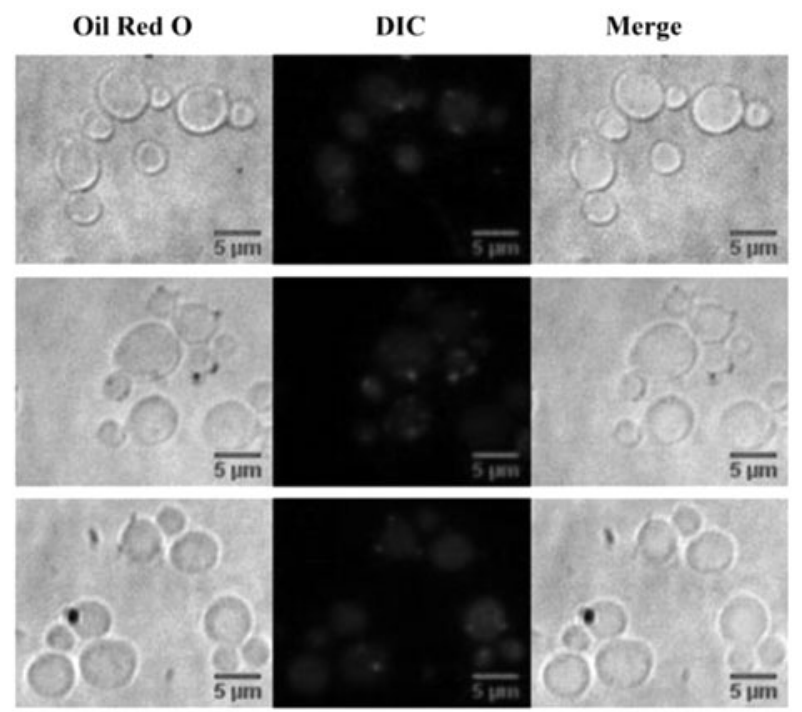

mga2s

B

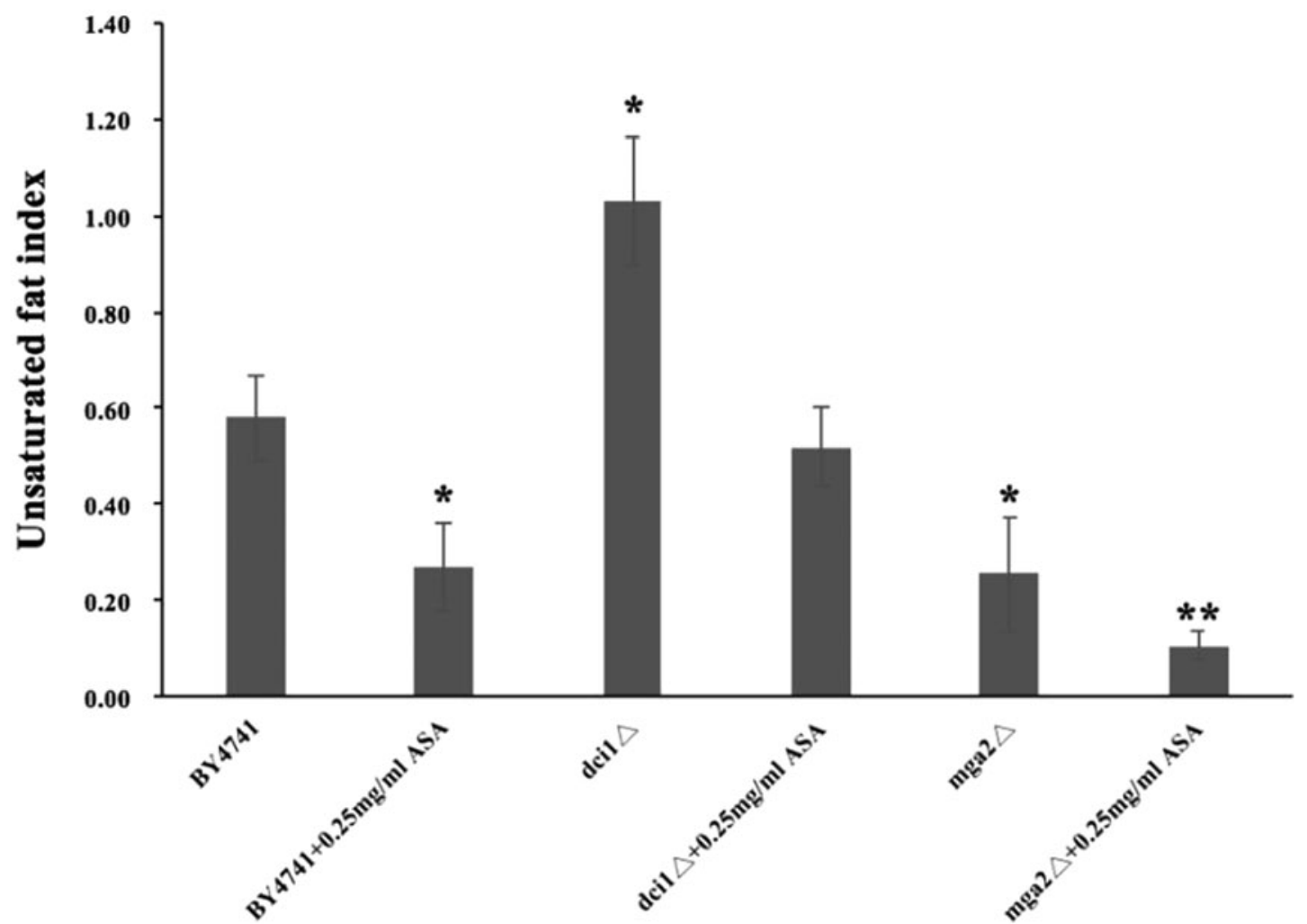

FIG. 3. Effect of aspirin on the cellular lipid accumulation in $d c i 1 \Delta$ and mga2 $\Delta$ mutants and fatty acid contents in yeast. (A) Intracellular lipid droplets were stained with Oil Red O and photographed by DIC microscopy and fluorescence microscopy with $\times 400$ magnification, scale bar is 2 and $5 \mu \mathrm{m}$. Concentration of aspirin was 0.125 and $0.25 \mathrm{mg} / \mathrm{mL}$, respectively. (B) The unsaturation index in the yeast BY4741 and mutant strains with different treatment were analyzed, as described in the Materials and Methods section. Values were expressed as mean \pm SD. ${ }^{*} p<0.05$, ${ }^{*} p<0.01$ (compared to wide-type control group).

Subsequently, we investigated the lipid accumulation in $d c i 1 \Delta$ and $m g a 2 \Delta$ with and without aspirin. As shown in Fig. 3A, aspirin had no effect on lipid accumulation in $d c i 1 \Delta$ and $m g a 2 \Delta$. To conclude, these data demonstrate that aspirin induces lipid accumulation by regulating $D C I 1$ and $O L E 1$ in yeast cells.

\section{Aspirin changes the components of fatty acids in yeast cells}

DCII and OLE1 genes are responsible for keeping the saturated and unsaturated fatty acid balance in yeast. ${ }^{30}$ To further evaluate whether aspirin inhibit yeast growth by 
disturbing fatty acid metabolism, we measured the content of fatty acids in BY4741, dcild, and mga2 $\Delta$ using GC-MS. The content of fatty acids was interfered by aspirin compared to the untreated cells (Table 3). After treatment with aspirin, the contents of saturated fatty acid in BY4741 increased significantly 1.25 times. Among unsaturated fatty acids, palmitoleic acid was dramatically decreased to $8.8 \%$. Myristic acid, arachidic acid, and behenic acid in mutants $d c i l \Delta$ increased greatly, while oleic acid decreased tremendously from $35.4 \%$ to $21.5 \%$ after treating with aspirin. However, there is no significant change in the content of fatty acids in $m g a 2 \Delta$. Then, we calculated the unsaturated fat index (unsaturated fat index $=$ ratio of unsaturated fat to saturated fat) of wild type and mutants, and found that the unsaturated fat index of wild type after treatment with aspirin dramatically decreased from 0.58 to 0.27 . The unsaturated fat index of $d c i l \Delta$ was higher than that of wild type. Intriguingly, the unsaturated fat index of $d c i 1 \Delta$ treated with aspirin decreased to the same level in BY4741. The unsaturated fat index of $m g a 2 \Delta$ further decreased significantly after treatment with aspirin (Fig. 3B).

\section{Aspirin causes membrane damage in yeast}

Fatty acids are one of the main components of yeast cell membranes $^{31}$ and play important roles in cell membrane fluid and membrane permeability. ${ }^{32}$ Aspirin was reported to interfere with the function of cell membrane by altering membrane fluidity. ${ }^{6}$ To assess the impact of aspirin on cell membrane integrity, PI was used as a fluorescent dye. The observation was detected by fluorescence microscopy. ${ }^{33}$ As shown in Fig. 4A and B, the percentage of dead cells (PI-stained) in BY4741 was 7.3\%. The percentage was increased to $41.5 \%$ after the cells were treated with $0.25 \mathrm{mg} / \mathrm{mL}$ aspirin. In the mutants $d c i 1 \Delta$ and $m g a 2 \Delta$, the ratio of PI-positive cells was $9.3 \%$ and $17.8 \%$, respectively. The percentage of dead cells in $m g a 2 \Delta$ increased to $59.7 \%$ after treatment with aspirin, whereas dead cells in dcils showed no significant change.

\section{The inhibitory effect of aspirin on C. albicans}

To test whether aspirin inhibits the growth of $C$. albicans via affecting the homologous genes of DCI1, MGA2, and
$O L E 1$, we performed quantitative real-time PCR analysis to explore the effect of aspirin on the expression of $O L E 1$ and SPT23, which is a key transcription factor of OLE1 in C. albicans. $^{34}$ Since the homologous gene of DCII in C. albicans has not been confirmed, the mRNA level of DCI1 could not be detected. SPT23 and OLE1 were both highly suppressed in dose-dependent manners (Fig. 5A, B).

Finally, we assessed the impact of aspirin on cell membrane integrity and lipid accumulation in $C$. albicans using the same methods performed in yeast $S$. cerevisiae. As shown in Fig. 5C and D, aspirin led to an increase in lipid accumulation in $C$. albicans in a dose-dependent manner. In addition, the results of impact of aspirin on cell membrane integrity indicate that aspirin also caused cell membrane damage in C. albicans (Fig. 5E, F).

\section{Discussion}

According to previous studies, aspirin can interfere with fatty acid metabolism by activating the enzyme in mitochondria, leading to the increase in usage of fatty acid and level of reactive oxygen species in animal cells. ${ }^{35,36}$ Herein, we further investigated the mode of action of aspirin on fatty metabolism in the model organism budding yeast and the pathogen $C$. albicans.

The results of screening the potential target genes of aspirin indicated that aspirin interfered with four groups of genes, including nonspecific drug resistance genes, cell membrane-related genes, cell wall integrity-related genes, and energy metabolism-related genes (Supplementary Table S1, Supplementary Fig. S1). It is noted that $M G A 2$, belonging to cell membrane related genes, is also involved in regulation of $O L E 1$ transcription and plays an important role in fatty acid metabolism in yeast. ${ }^{28}$ The lack of $M G A 2$ in the mutants showed that they were highly sensitive to aspirin. Meanwhile, our observations suggested that aspirin can induce cellular lipid accumulation in yeast (Fig. 1C, D). The findings were consistent with previous reports describing the effect of aspirin on fatty content in animal cells. ${ }^{29,37}$ This could be contributed to the effect of aspirin on fatty acid metabolism.

Aspirin can inhibit the release of fatty acids from both phospholipids and triglycerides, ${ }^{38}$ and inhibit the long chain

Table 3. Analysis of Content and Composition of Fatty Acid in BY4741, DCil $\Delta$, And $m g a 2 \Delta$

\begin{tabular}{|c|c|c|c|c|c|c|c|}
\hline \multirow[b]{2}{*}{ Fatty acid } & \multirow{2}{*}{$\begin{array}{c}\text { No. of } \\
\text { carbon atom }\end{array}$} & \multicolumn{2}{|c|}{ BY4741 (\%) } & \multicolumn{2}{|c|}{$\operatorname{dci1} \Delta(\%)$} & \multicolumn{2}{|c|}{$\operatorname{mga} 2 \Delta(\%)$} \\
\hline & & Control & $0.25 \mathrm{mg} / \mathrm{mL} \mathrm{ASA}$ & Control & $0.25 \mathrm{mg} / \mathrm{mL} A S A$ & Control & $0.25 \mathrm{mg} / \mathrm{mL} \mathrm{ASA}$ \\
\hline Lauric acid & $\mathrm{C} 12: 0$ & $0.4 \pm 0.2$ & $0.6 \pm 0.1$ & $0.2 \pm 0.1$ & $0.4 \pm 0.3$ & $0.3 \pm 0.1$ & ND \\
\hline Myristic acid & C14:0 & $1.7 \pm 0.2$ & $1.4 \pm 0.4$ & $0.8 \pm 0.2$ & $1.8 \pm 0.3 *$ & $1.4 \pm 0.1$ & $1.4 \pm 0.3$ \\
\hline Palmitoleic acid & C16:1 & $14.6 \pm 2.8$ & $8.8 \pm 1.1 *$ & $19.5 \pm 4.4$ & $12.9 \pm 2.1$ & $9.7 \pm 3.5$ & $5.6 \pm 1.1$ \\
\hline Palmitic acid & C16:0 & $38.6 \pm 2.0$ & $48.2 \pm 5.5^{*}$ & $30.0 \pm 4.7$ & $36.9 \pm 0.6$ & $50.2 \pm 6.2$ & $56.6 \pm 3.8$ \\
\hline Oleic acid & C18:1 & $21.7 \pm 5.0$ & $12.5 \pm 4.7$ & $35.4 \pm 3.7$ & $21.5 \pm 1.6^{*}$ & $10.3 \pm 4.4$ & $4.0 \pm 1.3$ \\
\hline Stearic acid & C18:0 & $20.8 \pm 5.6$ & $25.2 \pm 2.3$ & $12.8 \pm 3.2$ & $20.8 \pm 2.9$ & $28.2 \pm 3.6$ & $32.4 \pm 2.7$ \\
\hline Arachidic acid & C20:0 & $1.3 \pm 0.7$ & $1.7 \pm 1.2$ & $0.8 \pm 0.1$ & $1.9 \pm 0.5 *$ & ND & ND \\
\hline Behenic acid & $\mathrm{C} 22: 0$ & $1.1 \pm 0.33$ & $1.7 \pm 1.4$ & $0.6 \pm 0.2$ & $4.0 \pm 1.3^{*}$ & ND & ND \\
\hline
\end{tabular}

Values were expressed as mean \pm standard deviation.

${ }^{*} p<0.05$ (drug-treated group vs. corresponding control group).

ASA, acetylsalicylic acid; ND, not detected. 
A

ASA

$0.25 \mathrm{mg} / \mathrm{ml}$

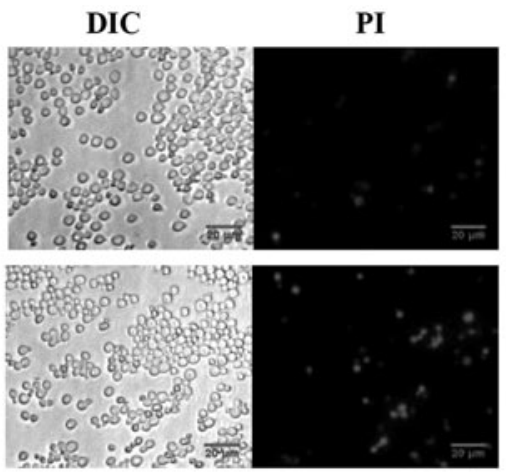

BY4741
DIC

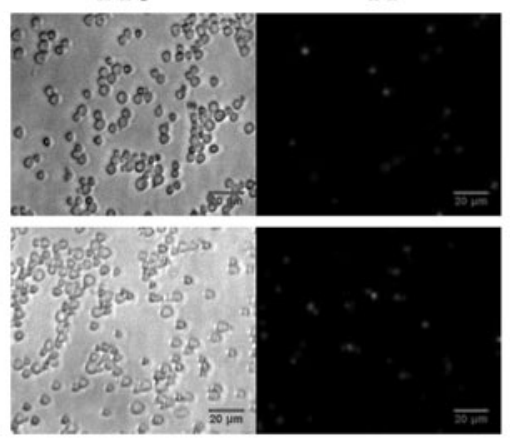

dci1 $\triangle$
DIC

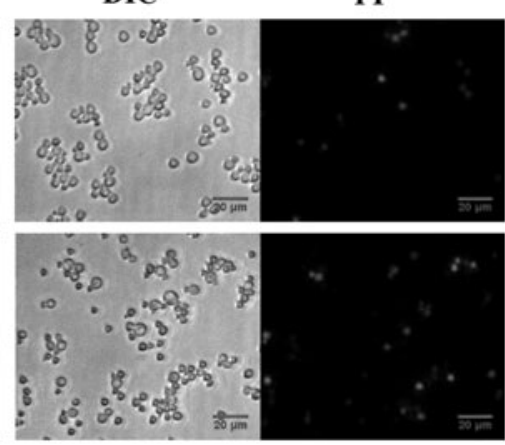

$m g a 2 \triangle$

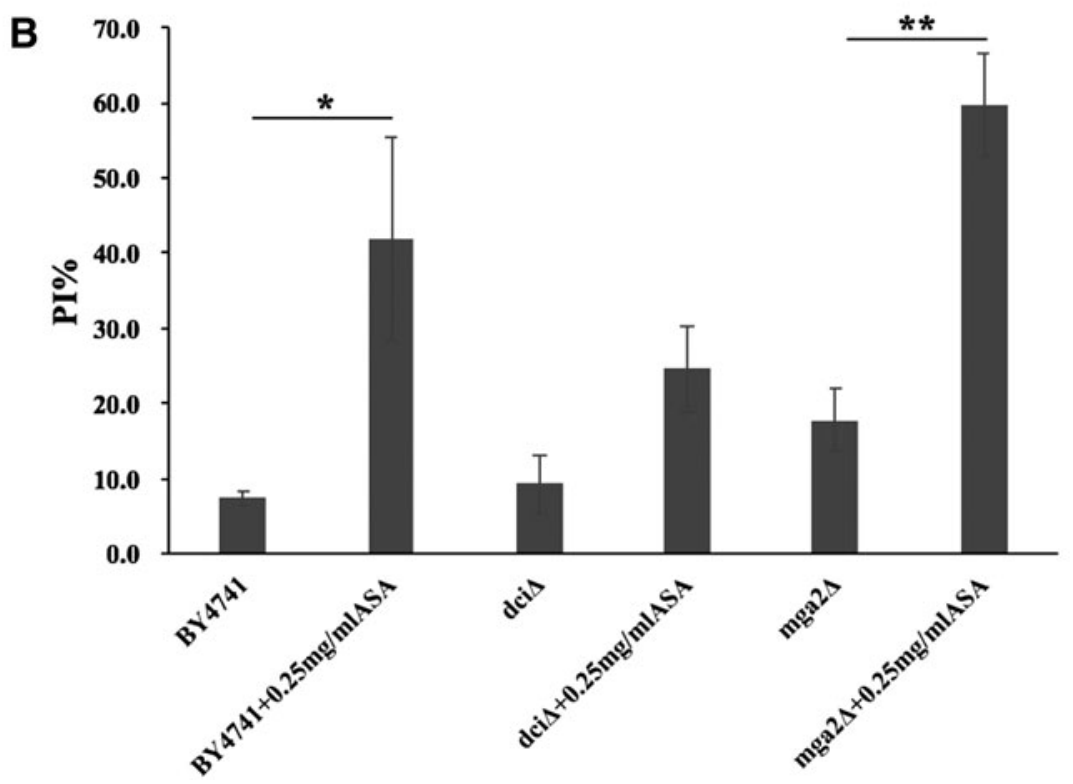

FIG. 4. Effects of aspirin on membrane integrity of wild-type BY4741 and mutants. (A) Membrane integrity of wild-type BY4741 and mutants. After 24 hours cultivating in SC presenting in 0 and $0.25 \mathrm{mg} / \mathrm{mL}$ aspirin, yeast cells were stained with PI for 15 minutes and observed using a fluorescent microscope with $\times 160$ magnification, scale bar is $20 \mu \mathrm{m}$. (B) Percentage of PI-stained cells shown in panel after 24 hours aspirin treatment. Values were expressed as mean \pm SD. $* p<0.05$, $* * p<0.01$ (drug-treated group vs. corresponding control group). PI, propidium iodide.

3-hydroxyacyl-CoA dehydrogenase, which is involved in the beta-oxidation of fatty acids. ${ }^{39,40}$ Fatty acid synthase has been identified to be a potential antifungal target. ${ }^{41}$ Pan et al. showed aspirin causes time-dependent inhibition and acetylation of allene oxide synthase that initiates plant oxylipin synthesis. ${ }^{42}$ He et al. and Hawley et al. proved that aspirin can regulate lipid metabolism by activating the AMP-activated protein kinase of AMPK pathway. ${ }^{35,43}$ In this study, we identified that $D C I 1$ and $M G A 2 / S P T 23$ genes can be the potential targets of aspirin by spot assay. Since $M G A 2 / S P T 23$ is an upregulator of the OLE1 gene, ${ }^{28,34}$ and $D C I 1$ and $O L E 1$ play the opposite roles in lipid metabolism, our results indicated that the effect of aspirin on lipid accumulation could be attributed to the alterations in the expression of DCII and OLE1 genes. Moreover, Vincent et al. found that the compound YTX-465 from 1,2,4-oxadiazole inhibited $O L E 1$ but was inactive to $S C D 1$, which is the human homolog of $O L E 1$. It indicates $O L E 1$ could be as a perspective target for antifungal agent. ${ }^{44}$
Fatty acids are ubiquitous in nature and carry out many functions involved in cell energy storage, membrane structure, and in various signaling pathways. ${ }^{45}$ The composition of saturated and unsaturated fatty acids plays an important role in affecting protein in cell activities, such as ion channels, receptors, and gene expression. ${ }^{46,47}$ In this study, DCI1 and OLE1 were found to be involved in the effect of aspirin on yeast. These two genes are associated with the synthetic pathway of the saturated and unsaturated fatty acids. ${ }^{30}$ Our data also verified these effects (Table 3 and Fig. 3A).

It is well known that unsaturated fatty acids are essential for maintaining cell membrane integrity and function and for adapting to environmental stress. ${ }^{48,49}$ Therefore, we assessed the effect of aspirin on yeast cell membrane integrity. Our results showed that aspirin causes loss of membrane integrity for passing the PI, suggesting aspirin leads to alteration in lipid composition in cell membrane. A co-relation has been observed between oxidative stress induced by aspirin and 
A

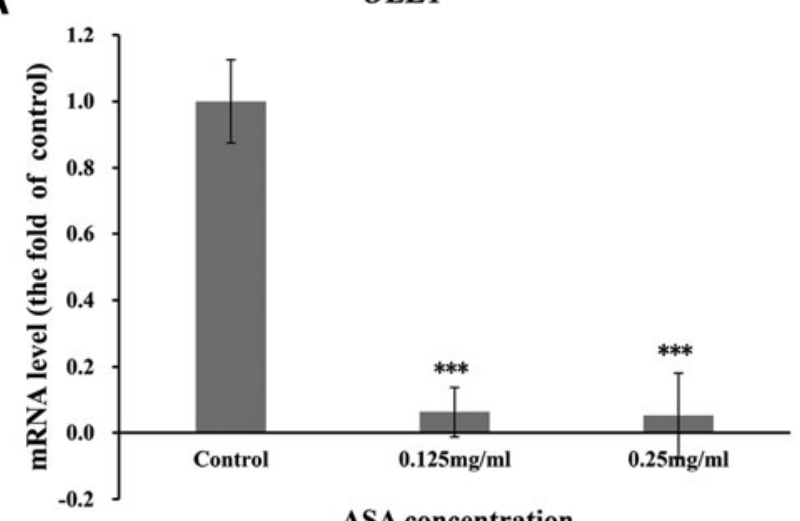

C

Control

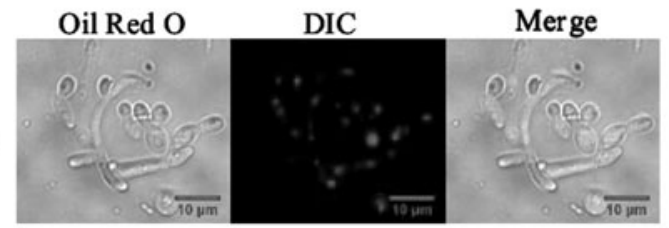

ASA

$0.125 \mathrm{mg} / \mathrm{ml}$

ASA

$0.25 \mathrm{mg} / \mathrm{ml}$
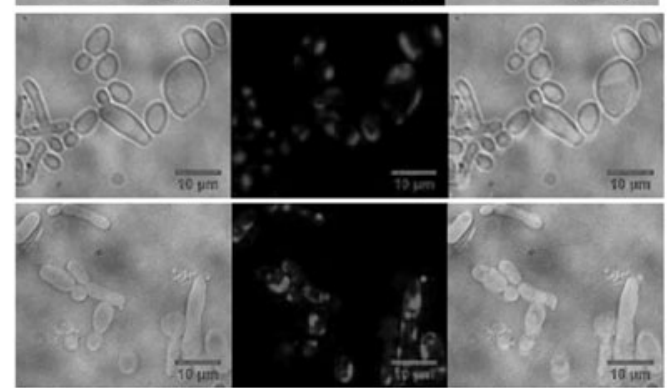

C. albicans

E

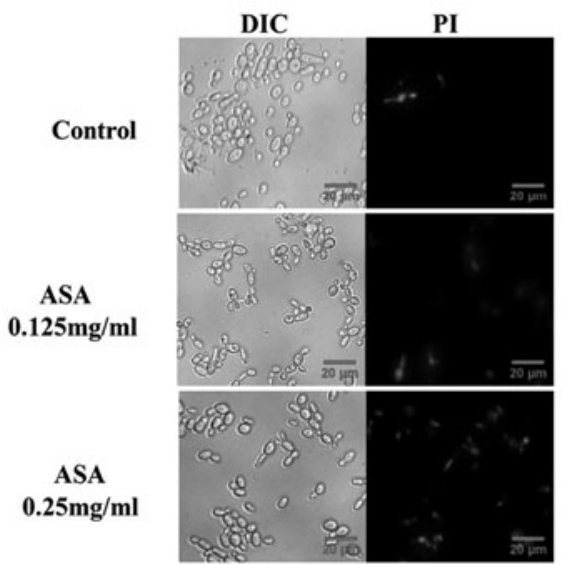

B

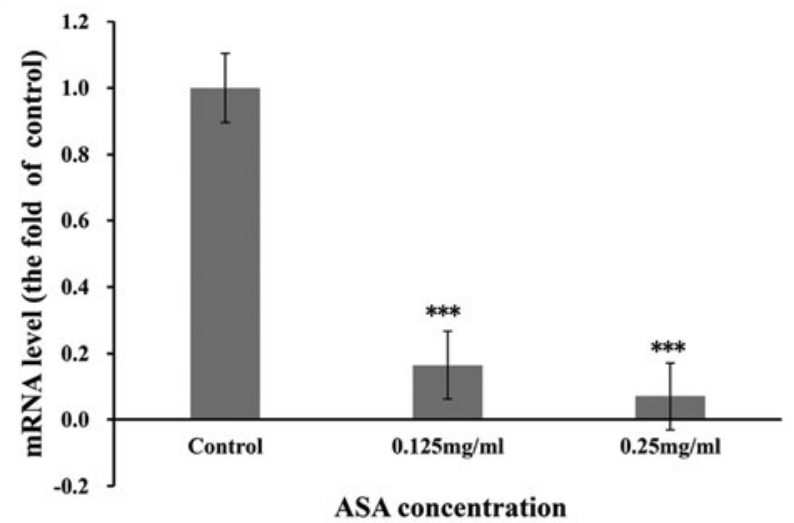

ASA concentration

D

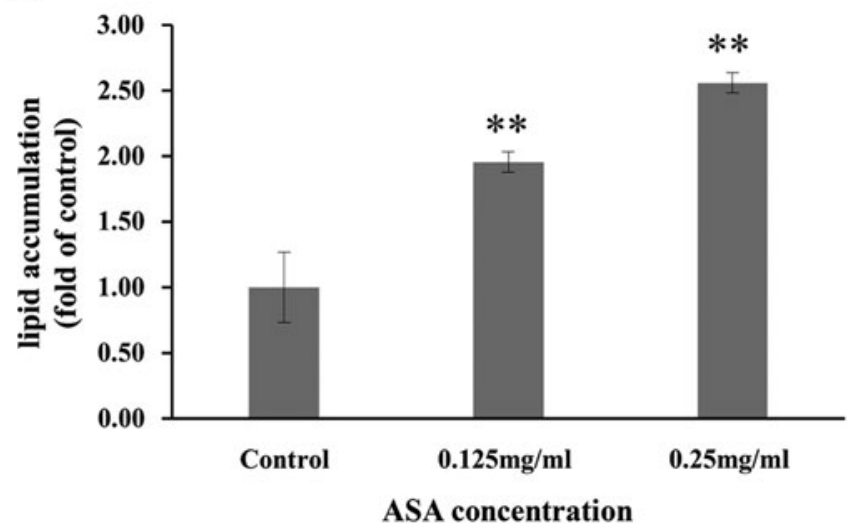

F

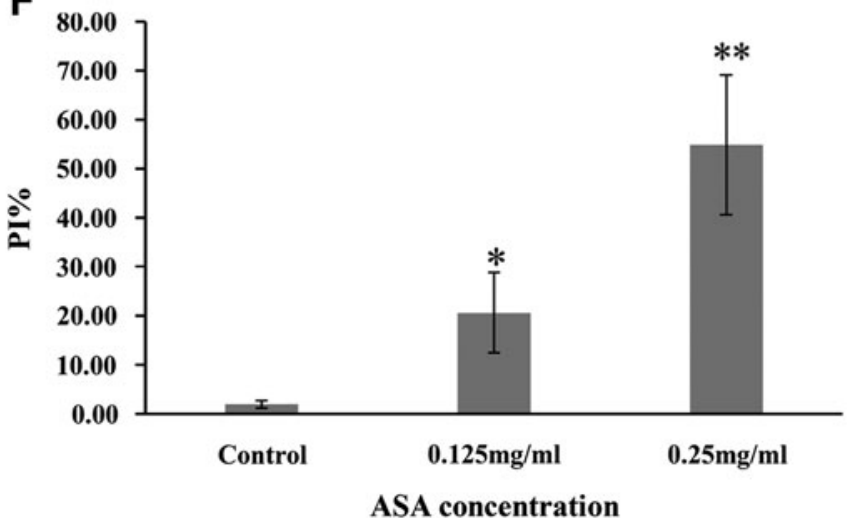

FIG. 5. Effect of aspirin on genes, cellular lipid accumulation, and membrane integrity in Candida albicans. (A, B) Quantitative real-time PCR analysis. The mRNA expression of SPT23 and OLE1 was confirmed by real-time PCR analysis and normalized to ACT1 RNA expression. Values were expressed as mean \pm SD. $* * * p<0.001$ (drug-treated group vs. corresponding control group). (C) Intracellular lipid droplets of $C$. albicans were stained with Oil Red O and photographed by DIC microscopy and fluorescence microscopy with $\times 400$ magnification, scale bar is $10 \mu \mathrm{m}$. Concentration of aspirin was 0.125 and $0.25 \mathrm{mg} / \mathrm{mL}$, respectively. (D) Quantification of lipid accumulation in C. albicans under 0.125 and $0.25 \mathrm{mg} / \mathrm{mL}$ aspirin treatment. Values were expressed as mean \pm SD. $* * p<0.01$ (drug-treated group vs. control group). (E) Membrane integrity of $C$. albicans. After 24 hours cultivating in SC presenting in $0,0.125$, and $0.25 \mathrm{mg} / \mathrm{mL}$ aspirin, C. albicans cells were stained with PI for 15 minutes and observed using DIC microscopy and fluorescence microscopy with $\times 160$ magnification. (F) Percentage of PI-stained cells shown in panel after 24 hours aspirin treatment. Values were expressed as mean \pm SD. $* p<0.05, * * p<0.01$ (drug-treated group vs. corresponding control group). 
cell membrane damage, which may suggest that the damage to the cell membrane could be due to the increased lipid peroxidation. ${ }^{50,51}$ Membrane fatty acid unsaturation plays an important role in protecting against oxidative stress. ${ }^{52}$ As the Fig. 3B shows, the decreasing unsaturated fat index in wild type and mutant type could be caused by oxidative stress induced by aspirin, leading to damage to the cell membrane. Fang et al. reported that overexpression of OLE1 enhances cytoplasmic membrane stability and confers resistance to cadmium in yeast. ${ }^{33}$ Our data indicated that the overexpression of $O L E 1$ also helps yeast cells increase the resistance to aspirin. But contradictory to our expectations, overexpression of OLE1 in dcil $\triangle$ mutants did not improve their resistance to aspirin. The reason might be attributed to the high levels of unsaturated fatty acids, which can inhibit the cell growth according to the previous report. ${ }^{52}$

Herein, our finding that aspirin interferes with fatty acid metabolism in yeast has also been further proven in C. albicans. Consistent with this model, aspirin caused cell membrane damage by inhibiting expression of $O L E 1$ in $C$. albicans cells. Obviously, aspirin exhibits an inhibitory effect on the fungal pathogen $C$. albicans. To sum up, our observations suggest that aspirin could cause lipid accumulation and damage to the cell membrane by interfering with the expression of DCI1 and OLE1, leading to the inhibition of the yeast $S$. cerevisiae cell growth. Additionally, the inhibitory effect of aspirin on OLE1 is conserved in C. albicans. These discoveries can be used as a novel strategy for antifungal drug design.

\section{Disclosure Statement}

No competing financial interests exist.

\section{Funding Information}

This work was supported by grants from the National Natural Science Foundation of China (31671309), and the Development Project of Qinghai Key Laboratory (2017ZJ-Y10).

\section{Supplementary Material}

Supplementary Figure S1

Supplementary Table S1

\section{References}

1. Awtry, E.H., and J. Loscalzo. 2000. Aspirin. Circulation 101:1206-1218.

2. Cryer, B., and M. Feldman. 1999. Effects of very low dose daily, long-term aspirin therapy on gastric, duodenal, and rectal prostaglandin levels and on mucosal injury in healthy humans. Gastroenterology 117:17-25.

3. Langley, R.E., and P.M. Rothwell. 2013. Biological markers: potential biomarker for aspirin use in colorectal cancer therapy. Nat. Rev. Clin. Oncol. 10:8.

4. Martin, S.J. 2007. Antimicrobial stewardship: the aspirin of the 21st Century. Expert Rev. Anti-Infect. 5:159161.
5. Keser, D., and A. Karataş. 2012. Effects of aspirin and acetaldehtde on longevity and metamorphosis duration of drosophila melanogaster. Fresen. Environ. Bull. 21:27582765 .

6. Alem, M.A.S., and L.J. Douglas. 2004. Effects of aspirin and other nonsteroidal anti-inflammatory drugs on biofilms and planktonic cells of Candida albicans. Antimicrob. Agents Chemother. 48:41-47.

7. Sapienza, K., and R. Balzan. 2005. Metabolic aspects of aspirin-induced apoptosis in yeast. FEMS Yeast Res. 5: 1207-1213.

8. Farrugia, G., W.H. Bannister, N. Vassallo, and R. Balzan. 2013. Aspirin-induced apoptosis of yeast cells is associated with mitochondrial superoxide radical accumulation and NAD (P) $\mathrm{H}$ oxidation. FEMS Yeast Res. 13: 755-768.

9. Botstein, D., and G.R. Fink. 2011. Yeast: an experimental organism for 21st Century biology. Genetics 189:695704.

10. Arlia-Ciommo, A., A. Piano, A. Leonov, V. Svistkova, and V.I. Titorenko. 2014. Quasi-programmed aging of budding yeast: a trade-off between programmed processes of cell proliferation, differentiation, stress response, survival and death defines yeast lifespan. Cell Cycle 13:33363349.

11. Fontana, L., L. Partridge, and V.D. Longo. 2010. Extending healthy life span-from yeast to humans. Science 328:321326.

12. Kohlwein, S.D. 2010. Obese and anorexic yeasts: experimental models to understand the metabolic syndrome and lipotoxicity. BBA-Mol. Cell Biol. 1801:222-229.

13. Menacho-Marquez, M., and J.R. Murguia. 2007. Yeast on drugs: Saccharomyces cerevisiae as a tool for anticancer drug research. Clin. Transl. Oncol. 9:221-228.

14. Birrell, G.W., G. Guri, A.M. Chu, R.W. Davis, and J.M. Brown. 2001. A genome-wide screen in Saccharomyces cerevisiae for genes affecting UV radiation sensitivity. Proc. Natl. Acad. Sci. U.S.A. 98:1260812613.

15. Tong, A.H.Y., G. Lesage, G.D. Bader, H. Ding, H. Xu, X. Xin, J. Young, G.F. Berriz, R.L. Brost, M. Chang, Y. Chen, X. Cheng, G. Chua, H. Friesen, D.S. Goldberg, J. Haynes, C. Humphries, G. He, S. Hussein, L. Ke, N. Krogan, Z. Li, J.N. Levinson, H. Lu, P. Menard, C. Munyana, A.B. Parsons, O. Ryan, R. Tonikian, T. Roberts, A.-M. Sdicu, J. Shapiro, B. Sheikh, B. Suter, S.L. Wong, L.V. Zhang, H. Zhu, C.G. Burd, S. Munro, C. Sander, J. Rine, J. Greenblatt, M. Peter, A. Bretscher, G. Bell, F.P. Roth, G.W. Brown, B. Andrews, H. Bussey, and C. Boone. 2004. Global mapping of the yeast genetic interaction network. Science 303:808813.

16. Lum, P.Y., C.D. Armour, S.B. Stepaniants, G. Cavet, M.K. Wolf, J.S. Butler, J.C. Hinshaw, P. Garnier, G.D. Prestwich, A. Leonardson, P. Garrett-Engele, C.M. Rush, M. Bard, G. Schimmack, J.W. Phillips, C.J. Roberts, and D.D. Shoemaker. 2004. Discovering modes of action for therapeutic compounds using a genome-wide screen of yeast heterozygotes. Cell 116:121-137.

17. Marton, M.J., J.L. DeRisi, H.A. Bennett, V.R. Iyer, M.R. Meyer, C.J. Roberts, R. Stoughton, J. Burchard, D. Slade, H. Dai, D.E. Bassett Jr., L.H. Hartwell, P.O. Brown, and S.H. Friend. 1998. Drug target validation and identification of secondary drug target effects using DNA microarrays. Nat. Med. 4:1293. 
18. Natter, K., P. Leitner, A. Faschinger, H. Wolinski, S. McCrait, S. Fields, and S.D. Kohlwein. 2005. The spatial organization of lipid synthesis in the yeast Saccharomyces cerevisiae derived from large scale green fluorescent protein tagging and high resolution microscopy. Mol. Cell. Proteom. 4:662-672.

19. Geisbrecht, B.V., K. Schulz, K. Nau, M.T. Geraghty, H. Schulz, R. Erdmann, and S.J. Gould. 1999. Preliminary characterization of Yor180Cp: identification of a novel peroxisomal protein of Saccharomyces cerevisiae involved in fatty acid metabolism." Biochem. Biophys. Res. Commun. 260:28-34.

20. Ogasawara, Y., S. Kira, Y. Mukai, T. Noda and A. Yamamoto. 2017. Ole1, fatty acid desaturase, is required for Atg9 delivery and isolation membrane expansion during autophagy in Saccharomyces cerevisiae. Biol. Open 6: 35-40.

21. Pan, X., D.S. Yuan, S.-L. Ooi, X. Wang, S. SookhaiMahadeo, P. Meluh, and J.D. Boeke. 2007. dSLAM analysis of genome-wide genetic interactions in Saccharomyces cerevisiae. Methods 41:206-221.

22. Pan, X., D.S.Yuan, D. Xiang, X. Wang, S. SookhaiMahadeo, J.S. Bader, P. Hieter, F. Spencer, and J.D. Boeke. 2004. A robust toolkit for functional profiling of the yeast genome. Mol. Cell 16:487-496.

23. Adeyo, O., P.J. Horn, S. Lee, D.D. Binns, A. Chandrahas, K.D. Chapman, and J.M. Goodman. 2011. The yeast lipin orthologue Pahlp is important for biogenesis of lipid droplets. J. Cell Biol. 192:1043-1055.

24. Schneiter, R., and G. Daum. 2006. Extraction of yeast lipids. Methods Mol. Biol. 313:41-45.

25. Liu, D., X.A. Zeng, D.W. Sun, and Z. Han. 2013. Disruption and protein release by ultrasonication of yeast cells. Innov. Food Sci. Emerg. 18:132-137.

26. Wang, S., J. Wang, X. Zhang, L. Hu, Z. Fang, Z. Huang, and P. Shi. 2016. Trivalent chromium alleviates oleic acid induced steatosis in SMMC-7721 cells by decreasing fatty acid uptake and triglyceride synthesis. Biometals 29:881892.

27. Malik, M.A., S.A. Al-Thabaiti, and M.A. Malik. 2012. Synthesis, structure optimization and antifungal screening of novel tetrazole ring bearing acyl-hydrazones. Int. J. Mol. Sci. 13:10880-10898.

28. Chellappa, R., P. Kandasamy, C.S. Oh, Y. Jiang, M. Vemula, and C.E. Martin. 2001. The membrane proteins, Spt23p and Mga2p, play distinct roles in the activation of Saccharomyces cerevisiae OLE1 gene expression fatty acid-mediated regulation of Mga2p activity is independent of its proteolytic processing into a soluble transcription activator. J. Biol. Chem. 276:43548-43556.

29. Yoshida, Y., S. Wang, and M. Osame. 1998. Aspirin induces short-chain free fatty acid accumulation in rats. Eur. J. Pharmacol. 349:49-52.

30. Gurvitz, A., A.M. Mursula, A.I. Yagi, A. Hartig, H. Ruis, H. Rottensteiner, and J.K. Hiltunen. 1999. Alternatives to the isomerase-dependent pathway for the $\beta$-oxidation of oleic acid are dispensable in Saccharomyces cerevisiae identification of Yor180c/DCI1 encoding peroxisomal $\Delta 3$, 5- $\Delta 2$, 4-dienoyl -CoA isomerase. J. Biol. Chem. 274: 24514-24521.

31. Van der Rest, M.E., A.H. Kamminga, A. Nakano, Y. Anraku, B. Poolman, and W.N. Konings. 1995. The plasma membrane of Saccharomyces cerevisiae: structure, function, and biogenesis. Microbiol. Rev. 59:304-322.
32. Ferreira, R., P.G. Teixeira, V. Siewers, and J. Nielsen. 2018. Redirection of lipid flux toward phospholipids in yeast increases fatty acid turnover and secretion. Proc. Natl. Acad. Sci. U.S.A. 115:1262-1267.

33. Fang, Z., Z. Chen, S. Wang, P. Shi, Y. Shen, Y. Zhang, J. Xiao, and Z. Huang. 2017. Overexpression of OLE1 enhances cytoplasmic membrane stability and confers resistance to cadmium in Saccharomyces cerevisiae. Appl. Environ. Microb. 83:e02319-16.

34. Oh, C.S., and C.E. Martin. 2006. Candida albicans Spt23p controls the expression of the Ole1p $\Delta 9$ fatty acid desaturase and regulates unsaturated fatty acid biosynthesis. J. Biol. Chem. 281:7030-7039.

35. Hawley, S.A., M.D. Fullerton, F.A. Ross, J.D. Schertzer, C. Chevtzoff, K.J. Walker, M.W. Peggie, D. Zibrova, K.A. Green, K.J. Mustard, B.E. Kemp, K. Sakamoto, G.R. Steinberg, and D.G. Hardie. 2012. The ancient drug salicylate directly activates AMP-activated protein kinase. Science 336:918-922.

36. Uppala, R., B. Dudiak, M.E. Beck, S.S. Bharathi, Y. Zhang, D.B. Stolz, and E.S. Goetzman. 2017. Aspirin increases mitochondrial fatty acid oxidation. Biochem. Biophys. Res. Commun. 482:346-351.

37. Murai, A., J. Okumura, and M. Furuse. 1996. Aspirin promotes hepatic triacylglycerol accumulation in essential fatty acid-deficient Japanese quail. Naunyn Schmiedebergs Arch. Pharmacol. 353:689-692.

38. Calder, P.C. 2001. Polyunsaturated fatty acids, inflammation, and immunity. Lipids 36:1007-1024.

39. Glasgowa, J.F., B. Middletonb, R. Moorea, A. Graya, and J. Hill. 1999. The mechanism of inhibition of $\beta$-oxidation by aspirin metabolites in skin fibroblasts from Reye's syndrome patients and controls. BBA-Mol. Basis Dis. 1454:115-125.

40. Glasgow, J.FT., and B. Middleton. 2001. Reye syndromeinsights on causation and prognosis. Arch. Dis. Child. 85: 351-353.

41. Li, X.C., A.S. Joshi, H.N. ElSohly, S.I. Khan, M.R. Jacob, Z. Zhang, I.A. Khan, D. Ferreira, L.A. Walker, S.E. Broedel Jr, R.E. Raulli, and R.L. Cihlar. 2002. Fatty acid synthase inhibitors from plants: isolation, structure elucidation, and SAR studies. J. Nat. Prod. 65:1909-1914.

42. Pan, Z., B. Camara, H.W. Gardner, and R.A. Backhaus. 1998. Aspirin inhibition and acetylation of the plant cytochrome P450, allene oxide synthase, resembles that of animal prostaglandin endoperoxide $\mathrm{H}$ synthase. J. Biol. Chem. 273:18139-18145.

43. He, Z., Y. Peng, W. Duan, Y. Tian, J. Zhang, T. Hu, Y. Cai, Y. Feng, and G. Li. 2015. Aspirin regulates hepatocellular lipid metabolism by activating AMPK signaling pathway. J. Toxicol. Sci. 40:127-136.

44. Vincent, B.M., D.F. Tardiff, J.S. Piotrowski, R. Aron, M.C. Lucas, C.Y. Chung, H. Bacherman, Y. Chen, M. Pires, R. Subramaniam, D.B. Doshi, H. Sadlish, W.K. Raja, E.J. Solis, V. Khurana, B. Le Bourdonnec, R.H. Scannevin, and K.J. Rhodes. 2018. Inhibiting stearoylCoA desaturase ameliorates $\alpha$-synuclein cytotoxicity. Cell Rep. 25: 2742-2754.

45. Liu, S., W. Ruan, J. Li, H. Xu, J. Wang, Y. Gao, and J. Wang. 2008. Biological control of phytopathogenic fungi by fatty acids. Mycopathologia 166:93-102.

46. Ntambi, J.M., and H. Bene. 2001. Polyunsaturated fatty acid regulation of gene expression. J. Mol. Neurosci. 16: 273-278. 
47. Litman, B.J., S.L. Niu, A. Polozova, and D.C. Mitchell. 2001. The role of docosahexaenoic acid containing phospholipids in modulating $\mathrm{G}$ protein-coupled signaling pathways: visual transduction. J. Mol. Neurosci. 16:237242.

48. You, K.M., C.L. Rosenfield, and D.C. Knipple. 2003. Ethanol tolerance in the yeast Saccharomyces cerevisiae is dependent on cellular oleic acid content. Appl. Environ. Microbiol. 69:1499-1503.

49. Rupčić, J., and G.Č. Jurešić. 2010. Influence of stressful fermentation conditions on neutral lipids of a Saccharomyces cerevisiae brewing strain. World J. Microb. Biotechnol. 26: 1331-1336.

50. Choi, S.S., S.H. Park, Y.B. Sim, and H.W. Suh. 2012. Effect of decursinol on the aspirin-induced gastric ulcer in mice. J. Korean Soc. Appl. Biol. Chem. 55:343345 .
51. Nku, C.O., G.O. Oghale, and I.O. Ajiwhen. 2015. Locomotor behaviour and anxiety in the open field and light/dark box in CD1 mice treated with aspirin, cataflam and ethanolic extract of cannabis sativa. Br. J. Med. Med. Res. 6:563.

52. Bossie, M.A., and C.E. Martin. 1989. Nutritional regulation of yeast delta-9 fatty acid desaturase activity. J. Bacteriol. 171:6409-6413.

Address correspondence to:

Ping Shi, PhD

State Key Laboratory of Bioreactor Engineering East China University of Science and Technology 130 Meilong Road Shanghai 200237

China

E-mail: ship@ecust.edu.cn 